\author{
Professor Marian STOICA, PhD \\ Department of Economic Informatics and Cybernetics \\ The Bucharest University of Economic Studies \\ E-mail: marians@ase.ro \\ Professor Bogdan GHILIC-MICU, PhD \\ Department of Economic Informatics and Cybernetics \\ The Bucharest University of Economic Studies \\ E-mail: ghilic@ase.ro \\ Professor Marinela MIRCEA, PhD \\ Department of Economic Informatics and Cybernetics \\ The Bucharest University of Economic Studies \\ E-mail: mmircea@ase.ro
}

\title{
THE TELEWORK PARADIGM IN THE IOE ECOSYSTEM - A MODEL FOR THE TELEWORKER RESIDENCE CHOICE IN CONTEXT OF DIGITAL ECONOMY AND SOCIETY
}

\begin{abstract}
Spectacular development of information and communication technology and ever-growing adoption of new paradigms of modern management (anthropocentric, holonic, fractal, systemic, product oriented etc.) corroborated with pandemic restrictions have led to an accelerated reorientation of the business environment towards new forms of remote work and activity. This is the main driving force behind the increasing share of telework in modern businesses. The infrastructure for the new telework paradigm is undoubtedly the global Internet network, enhanced by specific technologies of digital transformation like cloud computing, artificial intelligence, fog computing, Big Data, Internet of Things (IoT), Internet of Everything (IoE), augmented reality, etc. Out of this technological infrastructure, IoE stands out as a relatively new development, at the same time being the ecosystem of the current telework paradigm. This paper will approach these aspects considering the general economic, social and technological conditions on one side and the current state of knowledge on the other side. Thus, we will consider the main aspects of telework from the perspective of local experience, the main elements of IoE and finally, before conclusions and future developments, we will present a mathematically based model for choosing the residence in the context of telework in information society and digital economy. This model is based on the model of using the agricultural land formulated by German economist Johann Heinrich von Thünen.
\end{abstract}

Keywords: telework, IoE, IoT, cloud computing, math model, DESI.

JEL Classification: C61, J61, O33, R23

DOI: $10.24818 / 18423264 / 55.3 .21 .17$ 


\section{Introduction}

First formulated in the early ' 70 s, the general idea of remote working has taken shape and evolved into the concept, phenomenon, and paradigm known today as telework. The idea of remote management was first formulated by the parent of cybernetics, Norbert Wiener, who imagined in 1950 the case of an architect located in Europe that supervises the construction of a building in USA using a fax machine for communication. In 1980 Alvin Toffler nominated telework as a basic element of the third wave in his three-stage vision of human society development: first wave - agricultural society, second wave - industrial society and third wave - information society. The $80 \mathrm{~s}$ were a transition stage from industrial and post-industrial society to knowledge society. In a plastic expression, we could say that the end of ' 90 s marks the beginning of telework expansion in its various shapes (virtual telecommuting, virtual office, flexible work, semi-mobile commuting, etc.) (Ghilic-Micu and Stoica, 2016). Also noteworthy in this context is Isaac Asimov's vision of the development and control of society: the religious, scientific, commercial and psychological dimensions - much closer to historical and current reality.

The information society based on knowledge is the conclusion of the most modern and spectacular information and communication technologies invoked in telework processes. Even as we see remote work becoming the status-quo of current lucrative activities, we cannot forego the downsides and great dangers that can afflict the individual and family and/or society as a whole.

Compared to a recent previous epoch, today home work is no longer something novel, it has spread wide and far, with the "help" of health crisis. Adopted by companies, accepted by employees, telework is a long-term solution. Implementation of telework is a normality for $80 \%$ of global companies in the context of COVID-19 crisis, according to the most recent study by PricewaterhouseCoopers $(\mathrm{PwC})$ on 300 global organizations (Daniel and Nistor, 2020). The main three priorities in designing remote working adoption policy are health and security of employees, mentioned by $70 \%$ responders, improving employees' experience (65\%) and recruiting and retaining key talents $(60 \%)$.

In Romania, the same consulting company shows in its HR Status Report for October 2020 that employee productivity has increased since the implementation of home working for $30 \%$ of responding companies while $44 \%$ consider it to remain at the same level (Daniel and Nistor, 2020). The undoubted premise needed to ensure the continuity of this trend and maybe its acceleration is an increasingly more performant technological infrastructure (beyond the legal framework, teleworking employee rights etc.) This involves ambitious goals for authorities, as stated in the Strategy for European Union Common Digital Market adopted on May 6th 2015 (EUR-Lex, 2015). Such goals must be combined with adequate investment to lead to better performance in a relative short time. 
The Telework Paradigm in the IoE Ecosystem - A Model for the Teleworker Residence Choice in Context of Digital Economy and Society

\section{Current state}

Currently, due to spectacular development of information and communications technology on one side and pandemic crisis on the other side, home work is no longer an exception. Remote working has become an essential part of the new normal, companies being forced in many cases to adapt in order to keep working. Initial fears that work productivity will decrease were refuted in the first months of the pandemic, but it remains to be seen if the trend will hold on medium and long term. Many employees have started to feel the negative impact of lack of direct interaction with coworkers and have a desire to return to office. In any case, remote working remains a long-term option and most companies will keep using it.

These aspects have direct and indirect effects on housing market: more families track the market to purchase a land or a house in adjacent areas to big cities. This trend is supported by two factors: on one side a relatively uniform global telework legal frame and on the other side (at least in Europe) the existence and manifestation of a conservative spirit regarding the actual work place. Mobility and occupational migration is an obvious process of relocation of human capital in the current context of informational society based on intense exploitation of individual abilities (Dumitrescu, Ilie and Michaels, 2020).

In Romania, in 9 years (between 2010 and 2018) the average occupied population practicing total telework was $0.4 \%$ (approximately 32000 employees). In 2019 , the share of teleworkers in occupied population doubled, reaching $0.8 \%$. One reason is the establishment of legal framework by the adoption of law 81/2018 regarding teleworking activities (Parlamentul României, 2018). The law establishes the ways an employee can perform activities in teleworking regime. Teleworking is defined as a way of organizing the work in which the employee, regularly and voluntarily, performs the job-related activities in another place than the one organized by the employer, at least one day each month, using information and communications technology.

On European level, digital technologies change the way people communicate and also the way they live and work. The Covid-19 crisis gave EU a new impulse towards accelerating the technological transition. Digital solutions contribute to creation of jobs, education progress, stimulate competition and innovation and may improve the citizens' lives (Eurostat, 2021). Digital technology plays an essential part in transforming the European economy and society, to reach a climatically neutral Europe by 2050 , as agreed by European leaders.

Thus, as a consequence of December 2020 request of European Council, the European Commission has published on march 9th, 2021, the Europe's Digital Compass which states the digital ambitions of EU for 2030 in concrete requirements, based on four essential elements (Comisia Europeana, 2021):

$\checkmark$ Digitally competent citizens and professionals with high qualification in digital domain (today only $31 \%$ of European employees have advanced competencies in using the internet (European Commission, 2020)); 
$\checkmark$ Secure, high performance, sustainable digital infrastructure (Europe should have its own first quantum computer);

$\checkmark$ Digital transformation of enterprises (number of unicorn type startups - see decacorn and hectocorn - in EU should double);

$\checkmark$ Digitization of public services (by 2030 all essential public services should be available online).

The compass for European digital dimension establishes a solid governance structure, based on a monitoring system that creates annual reports as color codes. The goals will be enshrined into a strategic program that will be agreed by the European Parliament and the European Council.

\section{The Internet of Everything (IoE)}

The evolution of information and communications technology as well as the evolution of global Internet network leads to increasingly complex virtual connections, which encompass more objects and activities from the real world. Today everything can be connected, creating a new ecosystem that goes beyond the familiar concept of Internet of Things (IoT). Betting on the e-everything concept to describe this continuously evolving phenomenon, Cisco coined a new term: Internet of Everything (IoE) (Sakovich, 2019). According to the European Digital Compass, by 2030 all European households should have gigabyte connectivity and all populated areas should be covered by 5G technology. Also, Europe should cover $20 \%$ of the global production of latest generation sustainable semiconductors (today we see a crisis in car industry and elsewhere generated by the lack of semiconductors) (Comisia Europeana, 2021).

IoE concept is based on the idea of global, intelligent connectivity and knowledge. Any object may be equipped with digital functions and connected to the common network of other objects, individuals and processes in order to generate valuable information, exchange them with others and facilitate making important decisions. IoE represents the links between individuals, things, data and processes, all these combined into a correlated system, whose goals target new capabilities for new experiences and better-informed decisions (figure 1). The philosophy of IoE describes an ecosystem where billions of sensors accessorize billions of devices, cars and day-to-day objects, enabling them with extended interconnectivity options. Thus, individuals use things (equipment, devices, accessories etc.) generating data that constitutes inputs for various processes in various domains. Form individual, business and governmental perspective, these processes generate informational output that may lead to better informed decision making and development of new individual capabilities.

Main components of IoE are technology and services and constituting elements are: individuals - that transmit personal knowledge through web sites, applications or connected devices (social networks, medical assistance sensors or sports electronic accessories) towards artificial intelligence algorithms and other artificial intelligence technologies that analyze these data to "understand" the 
The Telework Paradigm in the IoE Ecosystem - A Model for the Teleworker Residence Choice in Context of Digital Economy and Society

human problems and provide relevant content for individual needs and businesses; things - pure IoT concept (various physical devices incorporated with sensors and actuators that generate data about their state and send it through network to corresponding destination); data - made compatible by synthesize/de-synthesize and aggregation/disaggregation operations that target the domain and the semantical side, classified and analyzed in an intelligent manner; and processes based on artificial intelligence, machine learning, social networks or other technologies that ensure the timeliness of transmitted information, guaranteeing a good usage of Big Data.

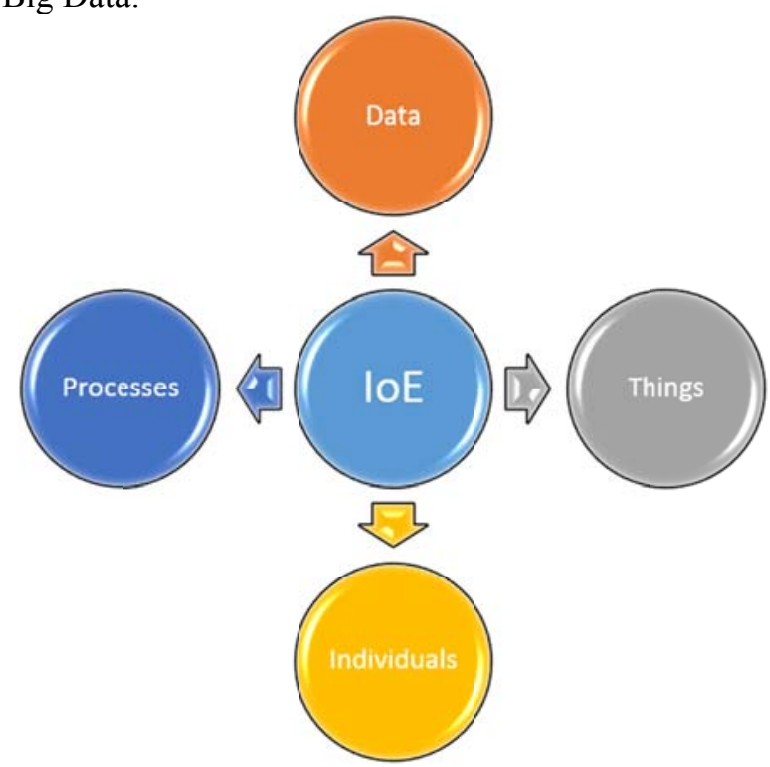

Figure 1. Concept of Internet of Everything (adaptation after (Sakovich, 2019))

These aspects make the two concepts (IoT vs. IoE) completely different. While IoT is focused on physical entities (interconnectivity of physical objects that send and receive data), IoE covers a much larger specter, including, beside IoT, numerous technologies and individuals as main actors. Unfortunately, both concepts share a common liability in security, the vulnerability of distributed systems remaining a big problem.

According to Statista, currently there are over 30 billion IoT devices worldwide and their number is expected to grow to over 75 billion by 2025 (Liu, 2020). All these devices will produce huge amounts of data that must be processed fast and in an efficient manner. Work market realities are changing with an accelerated rate, which is already significantly impacting the demographic movements in European Union and abroad. A significant image is provided by the evolution of DESI indicator (the Digital Economy and Society Index - figure 2) in 2020, computed on data available for 2019 (European Commission, 2021). 


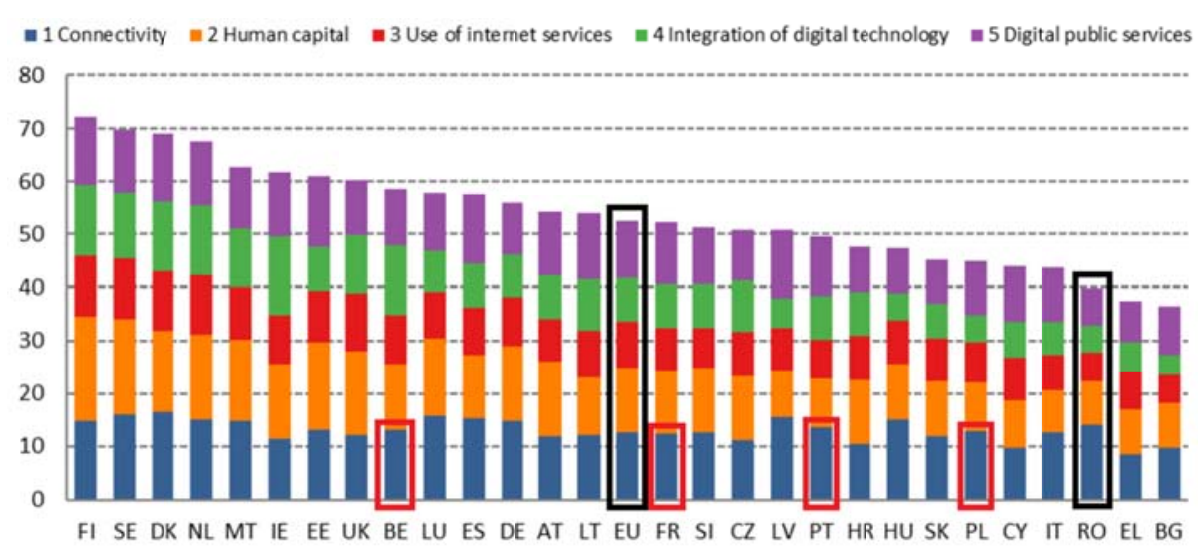

Figure 2. DESI evolution in 2020, for the 5 components

DESI is a composite index that sums up the relevant indicators regarding digital performance in Europe, tracking the EU member states' digital competitiveness (European Commission, 2021). The index for digital economy and society monitors the global European digital performance, detailing each country's digitization state and helping identify the domains that need priority investment and action. Desi is computed as a weighted average of measured values for five dimensions: connectivity, human capital, usage of Internet services, integration of digital technologies, and usage of public digital services. Unfortunately, Romania is again at the bottom of the chart (although one position up from 2019), followed only by Greece and Bulgaria. Still, on the connectivity component, Romania is well above the European average (figure 3), ahead of France, Belgium, Portugal or Poland (figure 2).

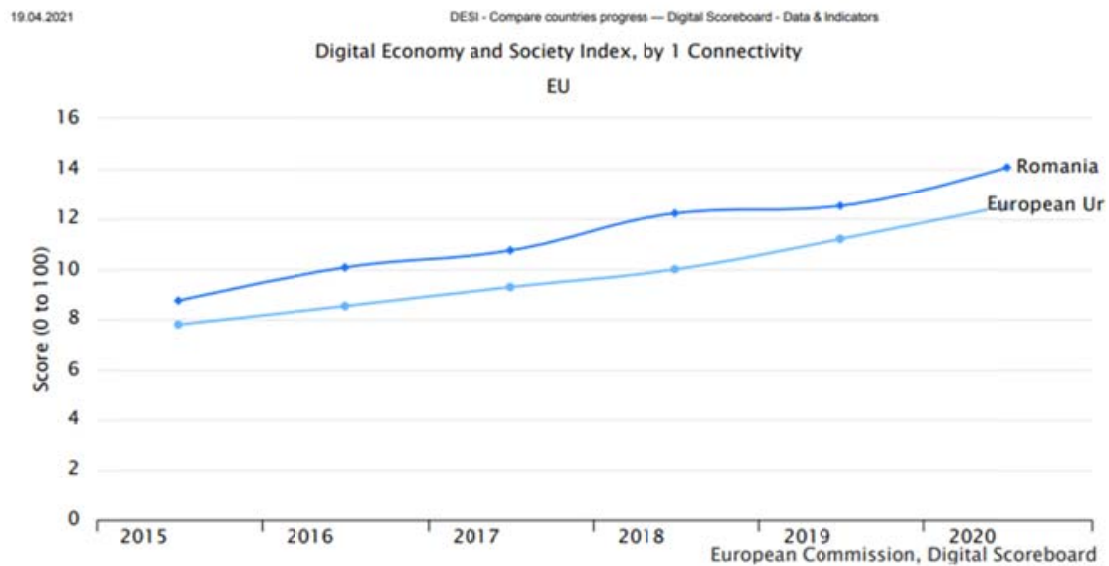

Figure 3. Connectivity dimension of DESI: Romania vs. UE 
The Telework Paradigm in the IoE Ecosystem - A Model for the Teleworker Residence Choice in Context of Digital Economy and Society

The domains of connectivity and human capital are considered the most relevant in defining the DESI index because they represent the infrastructure of digital society and economy. Connectivity refers to the degree of fixed broadband take-up, fixed broadband coverage, prices for fixed and mobile broadband communications.

Human capital is analyzed from the perspective of users' ability to use internet services and their advanced ICT abilities (European Commission, 2020) see the first essential direction of the European Digital Compass. In the last 5 years, this indicator in Romania has followed an upward trend, from 6.87 in 2015 to 8.29 in 2019. However, in terms of human capital, Romania is well below the European average (figure 4). Both invoked dimensions for the infrastructure of digital economy and society are equally pillars for wider adoption and development of teleworking. This has direct implications on the demographic dimension of digital economy and society. This is why in the following section we will propose a model for choosing the teleworker's residence in the context of technology and IoE governed society.

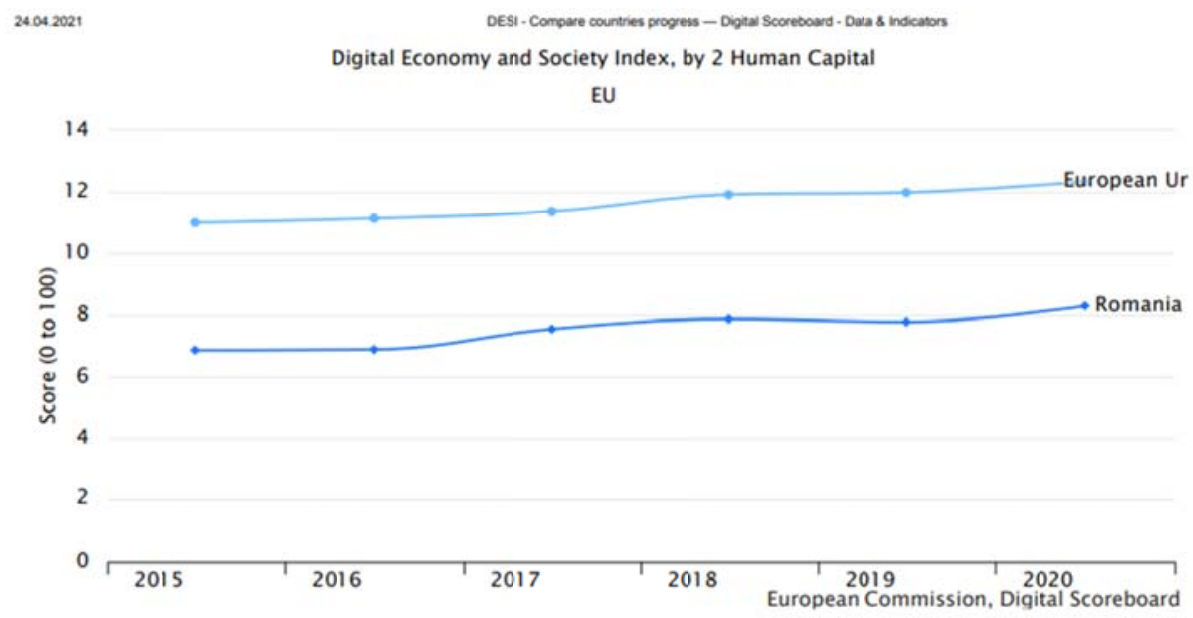

Figure 4. Human capital dimension of DESI: Romania vs. UE

The third dimension of the DESI index concerns the degree of use of internet services. This aspect of internet use by individuals increased during the COVID-19 pandemic. The widespread closure has resulted in recurrent access to social networks and entertainment platforms, as well as to teleworking services, ecommerce and e-government. For Romania, the degree of use of internet services also follows an upward trend in recent years but, at the same time, well below the European average (figure 5). 


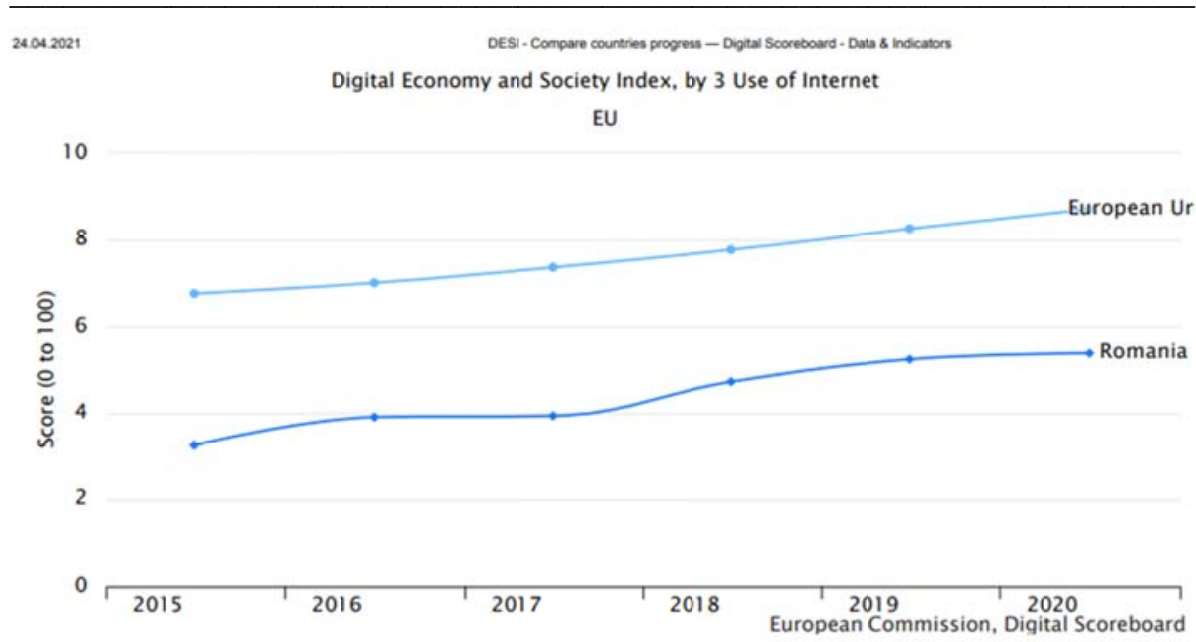

Figure 5. Use of internet dimension of DESI: Romania vs. UE

The fourth dimension of the DESI index measures the degree of adoption and integration of digital technology at the level of economic organizations. At European level, but also in Romania, the absolute value of this dimension has increased in the last 5 years, but especially during the pandemic period. As governments have taken steps to reduce social interaction, companies have had to adapt by introducing forms of teleworking. SMEs with a low level of digital technology find it difficult to give their staff the opportunity to work from home. One of the main obstacles to the adoption of digital technologies in small and medium-sized organizations is the digital knowledge gap, caused by low levels of digital literacy among owners, managers and employees.

The last but not the least important dimension of the DESI composite index is the use of digital public services. This dimension is identified in many situations with the degree of digitization of services of public interest or, more forgetting with e-government. A crisis situation such as the one we are going through shows once again how important it is to ensure the continuation of government activities when there are measures of social distancing. At European level, a successful exit strategy from the current pandemic will require solid digital public services (cloud computing, big data, artificial intelligence, etc.) in all Member States.

In most countries, the implementation of e-government has also led to the creation of laws requiring institutions to use e-services. For example, in some countries, including Romania, some institutions have to respond to e-mail requests within a fixed period. This has led to an increase in the number of applications received by the institutions. E-government also comes with new procedures that will require the use of a legal basis (Stoica and Ghilic-Micu, 2020). At the same time, in Romania, an economic organization wishing to participate in public tenders must use the electronic signature to access the documentation for the award of public works, products or services contracts. 
The Telework Paradigm in the IoE Ecosystem - A Model for the Teleworker Residence Choice in Context of Digital Economy and Society

Although overall the indicator on digital public services Romania is on an increasing trend, from a score of $31 \%$ in 2015 to $48.4 \%$ in 2020 , its level stands at $67.2 \%$ of the European average. However, for the sub-indicator DESI 5a1 - eGovernment Users, Romania is well above the European average with a maximum reached in 2016 of $94 \%$ (figure 6).

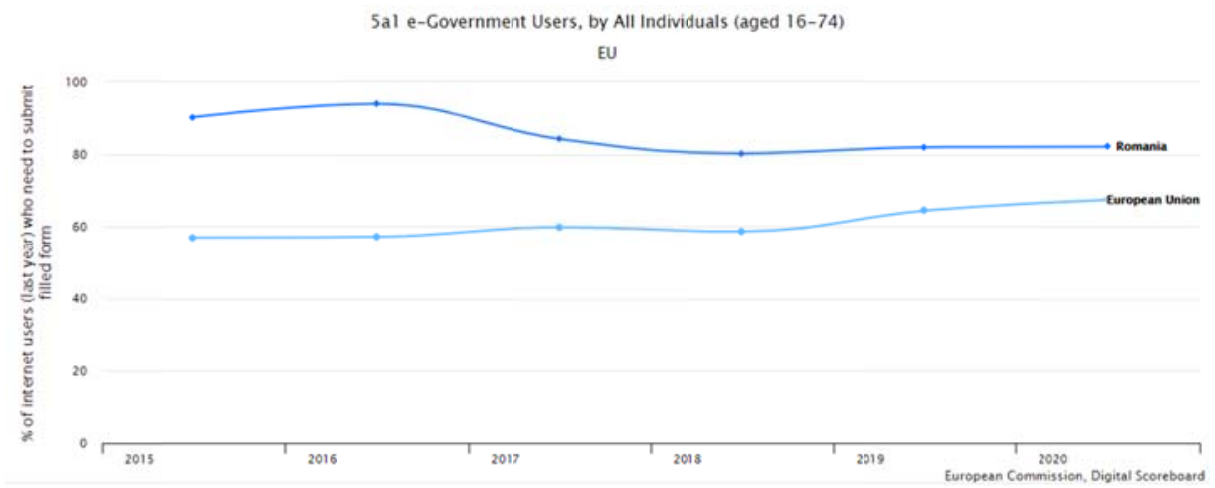

Figure 6. DESI 5a1 indicator (e-Government Users): Romania vs. UE

The value of the e-Government Users indicator is measured for internet service users in the 16-74 age group who, during a financial year, had to complete and submit at least one online form. Among the digital public service applications that work successfully in Romania, we mention Collaborative information system for a performing environment for public procurement - SICAP, National Agency for Fiscal Administration - NAFA, National Electronic System for Online Payment with Banking Cards - SNAP.

\section{A model for the teleworker residence choice in context of digital economy and society}

Whether a direct effect of pandemic restrictions or not, it is obvious that telework reduces the amount of daily commute. Long term effects will include changes in the residential areas located far from the work places, decreasing the total annual distance traveled for commute. The effect of residential changes is more visible metropolitan areas with low temporal variations of land price, which was anyway the trend of the last years. This aspect is obvious both in the residence area of individuals and in commercial areas. A good example in Bucharest's metropolitan area is eMAG (largest online retailer in Romania), that relocated its main logistic center $20 \mathrm{~km}$ from Bucharest, on A1 highway.

Telework was often suggested as a solution to decrease traffic congestion, energy consumption and air pollution by reducing the commute. Some critics argues that these benefits are countered by the high number of personal travels, considering the low share of work-related travels on local plan and changes in 
transportation alternatives. Also, it was argued that telework benefits for transportation system can further be diminished by increased flexibility in choosing the residence. It is expected that this flexibility encourages choosing a residence that is farther away from the work place, which will lead to increased traffic during days when employees go to the work place. In the worst case, distance traveled after relocating the residence can end up being longer than it previously was.

In (Nilles, 1998) Jack M. Nilles presents the results of a pilot project from California, USA, regarding telework and the intention of adopting it. The project lasted two years. The study revealed that $6 \%$ of the teleworkers moved or plan to move to a distance higher than 50 miles $(\sim 80.5 \mathrm{~km})$ from the work place. Still, there is no significant difference between the number or distance of travels to work place between the current situation and the project control group. Also, in (Mokhtarian, 1990), Patricia Lyon Mokhtarian shows that in the same area (San Diego, California) there is a relatively low percentage of participants that consider telework the main reason for relocating 2 or 3 times farther away from the work place, compared to current residence. When these relocations happen and telework frequency does not change, this will lead to an increase in commute.

In the following section we propose a theoretical research of residential changes induced by telework for monocentric metropoles, where employees work in the center. This theory regarding a model for choosing the residence provides qualitative and quantitative estimations of the importance of effects induced by the residence choice for diminishing telework benefits for transportation system (Alexa et al, 2019). More precisely, while telework effects on choosing the residence may be significant, they are moderated regarding the efficiency of reducing urban travels to the work place.

Thus, in the vision of William Alonso (Alonso, 1960), the model for choosing a residence, derived from the model of using agricultural land formulated by German economist Johann Heinrich von Thünen (author of mathematical theory of marginal productivity (Von Thünen, 2009)) states that residences are chosen such that the expenses for housing and work commute are minimized. Thus, for a monocentric metropolis like Bucharest, the cost will be computed as:

where

$$
C(d)=h+A \cdot R(d)+c_{T} \cdot T \cdot d / r
$$

C(d) is the total cost of residence location, computed as a function of the distance from the center of the metropolitan area;

$\mathbf{h}$ is the housing cost;

$\mathbf{A}$ is the area of the desired land (assumed constant);

$\mathbf{R}(\mathbf{d})$ is the cost of one land unit as function of its location;

$\mathbf{c}_{\mathrm{T}}$ is the cost per unit of distance traveled;

$\mathbf{T}$ is the number of one-way travels in a year (for example, from home to work place);

d is the distance between the residence and the work place in the metropolis center; 
The Telework Paradigm in the IoE Ecosystem - A Model for the Teleworker Residence Choice in Context of Digital Economy and Society

$\mathbf{r}$ is the local discount rate (may be deduced from fidelity points awarded by local gas stations, for example).

Considering the local specifics of national methodological regulations regarding public employees' settlement of transportation expenses (Ministry of Justice, 2013), then the cost for distance unit becomes $\mathbf{c}_{\mathbf{T}}=7.5 \% \cdot 2 \mathrm{~d} \cdot \mathrm{pc}$, where $\mathrm{pc}$ is the price of one liter of fuel. Thus, relation (1) becomes:

$$
\mathrm{C}(\mathrm{d})=\mathrm{h}+\mathrm{A} \cdot \mathrm{R}(\mathrm{d})+7.5 \% \cdot 2 \mathrm{~d} \cdot \mathrm{pc} \cdot \mathrm{T} \cdot \mathrm{d} / \mathrm{r}
$$

National methodological regulation regarding settlement of transportation expenses may be as well adopted by employers when teleworking projects are implemented. Since it is assumed that residence choice is meant to minimize total expenses, deriving the above relation leads to:

$$
\frac{d C(d *)}{d d}=0=A \frac{d R(d *)}{d d}+\frac{c_{T} T}{r}=A \frac{d R(d *)}{d d}+\frac{7.5 \% \cdot 2 \mathrm{~d} \cdot \mathrm{pc} \cdot T}{r}
$$

or

$$
\frac{d R(d *)}{d d}=-\frac{c_{T} T}{A r}=-\frac{7.5 \% \cdot 2 \mathrm{~d} \cdot \mathrm{pc} \cdot T}{A r}
$$

where mathematical derivatives are evaluated at $\mathbf{d}^{*}$, the distance for the cheapest location. Since the land price is inversely proportional to the distance to metropolitan center, $\mathbf{d R}\left(\mathbf{d}^{*}\right) / \mathbf{d d}$ is a negative value. Considering telework reduces the number of annual travels $\left(\mathbf{T}_{1}<\mathbf{T}_{\mathbf{0}}\right)$, then:

$$
\left(\frac{d R(d *)}{d d}\right)_{T_{0}}<\left(\frac{d R(d *)}{d d}\right)_{T_{1}}<0
$$

We can assume that land price decreases exponentially, so:

$$
\mathrm{R}(\mathrm{d})=\mathrm{R}_{0} \cdot \mathrm{e}^{-\mathrm{kd}}
$$

where $\mathbf{R}_{\mathbf{0}}$ is the price in the center of the metropolitan area and $\mathbf{k}$ is the diminishing constant. In conclusion,

$$
\frac{d R(d)}{d d}=-R_{0} k e^{-k d}
$$

Combining equations (3) and (6) we get:

$$
R_{0} k e^{-k d *}=\frac{c_{T} T}{A r}=\frac{7.5 \% \cdot 2 \mathrm{~d} \cdot \mathrm{pc} \cdot T}{A r}
$$

where $\mathbf{d}^{*}$ is the lowest location cost. This can be reduced to: 


$$
e^{k d *}=\frac{A r R_{0} k}{c_{T} T}=\frac{A r R_{0} k}{7.5 \% \cdot 2 \mathrm{~d} \cdot \mathrm{pc} \cdot T}
$$

or

$$
d *=\frac{\ln \left(\frac{A r R_{0} k}{c_{T}}\right)}{k}-\frac{\ln T}{k}=\frac{\ln \left(\frac{A r R_{0} k}{7.5 \% \cdot 2 \mathrm{~d} \cdot \mathrm{pc}}\right)}{k}-\frac{\ln T}{k}
$$

Note that this relation has a constant that does not change with the number of travels to work place and a term that logarithmically grows with the number of travels to the work place.

It is important to measure the change in residential locations induced by switching to telework. Next, we will assume that only part of the activity is performed as telework. The employee remains at the residence or works close to it most of the work week, but has to physically report to the work place the rest of the work days. To examine this situation, we can define the variation in location cost given by equation $\Delta \mathbf{d}^{*}=\mathbf{d}^{*}\left(\mathbf{T}_{\mathbf{1}}\right)-\mathbf{d} *\left(\mathbf{T}_{\mathbf{0}}\right)$. Replacing this in equation (9), we get:

$$
\Delta d *=\frac{\ln \left(T_{0}\right)-\ln \left(T_{1}\right)}{k}=\frac{\ln \left(T_{0} / T_{1}\right)}{k}
$$

Note that this change of equilibrium is affected only by the change in travels to work place and decrease of land price. Other factors that count in the initial decision on location do not affect the magnitude of change in the equilibrium of lowest cost location.

\section{Telework impact on traveled distances}

Let's define the annual traveled distance by car, in kilometers, as: $\mathbf{D A P}(\mathbf{T})=\mathbf{T} \times \mathbf{d}^{*}$, where $\mathbf{T}$ and $\mathbf{d}^{*}$ have the same meaning as above. The variation of annual traveled distance for year $\mathbf{T}_{1}$, after introduction of telework, compared to a previous year $\mathbf{T}_{\mathbf{0}}$, is:

$$
\Delta \operatorname{DAP}\left(\mathrm{T}_{1}\right)=\operatorname{DAP}\left(\mathrm{T}_{1}\right)-\operatorname{DAP}\left(\mathrm{T}_{0}\right)=\mathrm{T}_{1} \mathrm{~d}_{1}^{*}-\mathrm{T}_{0} \mathrm{~d}_{0}^{*}
$$

where $\mathbf{d}_{\mathbf{0}}{ }^{*}$ and $\mathbf{d}_{\mathbf{1}}{ }^{*}$ are distance from lowest cost locations before and after telework was introduced. Note that $\Delta \mathbf{d}^{*}=\mathbf{d}_{\mathbf{1}}{ }^{*}-\mathbf{d}_{\mathbf{0}}{ }^{*}$, so expression (11) may be rewritten as:

$$
\Delta \operatorname{DAP}\left(\mathrm{T}_{1}\right)=\mathrm{T}_{1} \Delta \mathrm{d}^{*}+\mathrm{d}_{0}^{*} \cdot\left(\mathrm{T}_{1}-\mathrm{T}_{0}\right)
$$

Combining equations (10) and (12) we get:

$$
\Delta D A P\left(T_{1}\right)=T_{1} \frac{\ln \left(T_{0} / T_{1}\right)}{k}+d_{0} *\left(T_{1}-T_{0}\right)
$$

as a final prediction for the change in annual travelled distance, by car, to the work place in the metropolitan center. 
The Telework Paradigm in the IoE Ecosystem - A Model for the Teleworker Residence Choice in Context of Digital Economy and Society

We must also consider the financial effect of reducing the travelled distance for the teleworker, who can transfer the economies into telecommunication and work equipment maintenance expenses (Handy, 1993). The effect of residential changes on diminishing effects of teleworking on transportation system for a monocentric metropolis was researched using a simple economic model. The amplitude of this effect is maximum for average levels of teleworking in metropolitan areas with linear depreciation of land prices compared to the center. Also, in the context of IoE technological context, the variables of an economic model that considers DESI in its 5 dimensions are different: alternate energy sources, electrical vehicles etc.

In normal pre-pandemic conditions, teleworking popularity in European Union (EU27) was low. In 2019 the total percentage of occupied population involved exclusively in teleworking was no more than 5.4\% (Milasi, GonzálezVázquez and Fernández-Macías, 2021). Also, only $15 \%$ of total occupied population of EU27 ever tried teleworking. Recent studies (Fana et al, 2020) reveal a significant increase of this percentage. Since the start of COVID-19 pandemic, working from home has become the new normal for millions of employees in EU and world-wide. Early estimations of Eurofound (Ahrendt et al, 2020) suggest that almost $40 \%$ of current EU employees have switched to exclusive telework. This has direct and obvious implications on DAP indicator.

Residential change is probably a self-regulating phenomenon: many would prefer not to move too far away, unless they do telework often enough to reduce car travels. For others, there may be more important reasons than work related travels (for example, enhanced recreation opportunities in the new location, advantages for some family members, medical reasons etc.).

Analyzed effects are considered independent from local travels, nearby the residence and chained travels. Many factors were ignored, like resistance to short term relocation and behavior hypothesis assumed by Alonso's pure model (Alonso, 1964), who does not take into account changes in travels for those that live and work in suburban areas. In any case, this effect should manifest itself for residences farther away from the metropolis center than the traditional work place.

This model showcases a mechanism that, in a way, cancels the benefic effects of teleworking. The same mechanism has implications on the land use policies because an increase in teleworking encourages relocation to the outskirts of metropoles, which leads to increased pressure for development in these areas. The pandemic period, corroborated with spectacular development of technology and emergence of IoE have generated exactly this phenomenon: accelerated real estate and commercial development of outskirts of big cities.

\section{Conclusions and further research}

Generally, digitization facilitates creation of millions of intelligent and automated hardware devices. IoE range of devices is continuously growing and industries change, unavoidably. For sure we will see the future of ubiquitous 
connectivity. This will not dramatically change the way we do business, but will help provide better services and create better products. New requirements of emergent technologies are the driving force behind ICT development. Internet of things is a continuously growing industry that requires more efficient ways of managing data transmission and processing. European Union desires that by 2030 at least $80 \%$ of adults have basic digital competences (today more than a third of active work force in Europe has no basic digital competencies, even though most work places require such competencies) and use an electronic identification solution. Also, EU wants to have at least 20 million specialists involved in ICT sector. 10000 high security and climatically neutral edge computing nodes should be installed. By 2030 three out of four European companies should use cloud computing services, big data systems and artificial intelligence and over $90 \%$ of SMEs should reach at least the basic level of digital technologies adoption (Comisia Europeana, 2021).

In this technological context, remote working finds a natural place: benefits from the infrastructure, is legally regulated, properly remunerated and has a real growth potential. The impact will be obvious and on long term, both regarding the nature of work and the social perspective, with significant influences on the individual and the society as a whole. An important growth of digital economy will be recorded as instrument of mediating the gaps between states, in spite of regulations that put pressure and become barriers (see GDPR regulations for individuals and NIS for companies). In this context the model of choosing the residence by teleworkers may be a starting point.

As research direction, one of the approaches that may satisfy the demands of an increasingly higher number of interconnected devices is fog computing. This technology / paradigm uses local computer resources instead of remote resources, with more efficient and performant processing, reducing eventual problems linked to bandwidth. Companies should compare cloud computing to fog computing to take maximum advantage of emergent opportunities and monetize the real potential of technologies.

\section{REFERENCES}

[1] Ahrendt, D., Cabrita, J., Clerici, E., Hurley, J., Leončikas, T., Mascherini, M., Riso, S., Sándor, E. (2020), Living, Working and COVID-19. Eurofound, https://www.eurofound.europa.eu/publications/report/2020/living-working-andcovid-19;

[2] Alexa, D., Cismas, L.M., Rus, A.V., Pop Silaghi, M.I. (2019), Economic Growth, Competitiveness and Convergence in the European Regions. A Spatial Model Estimation; Economic Computation and Economic Cybernetics Studies and Research; ASE Publishing; 53(1): 107-124;

[3] Alonso, W. (1960), A Theory of the Urban Land Market. Papers and

Proceedings of the Regional Science Association, 6(1): 149-157; 
The Telework Paradigm in the IoE Ecosystem - A Model for the Teleworker Residence Choice in Context of Digital Economy and Society

[4] Alonso, W. (1964), Location and Land Use. Toward a General Theory of Land Rent. Publications of the Joint Center for Urban Studies of the Massachusetts Institute of Technology (MIT) and Harvard University, Harvard University Press, 204;

[5] Comisia Europeană (2021), Deceniul digital al Europei: Comisia trasează calea către o Europă autonomă din punct de vedere digital până în 2030. Bruxelles, https://ec.europa.eu/commission/presscorner/detail/ro/IP 21_983; [6] Daniel, A., Nistor, I. (2020), PwC Survey: 80\% of Companies Anticipate Remote Work as the New Norm on the Labour Market. PWC, https://www.pwc.ro/en/press-room/press-release-2020/pwc-survey--80--ofcompanies-anticipate-remote-work-as-the-new-n.html; [7] Dumitrescu, C.I., Ilie, I.R., Michaels, E. (2020), Burden-sharing and Accommodation of Migrants in the EU-A Simulation Based on Factorial Designs. Economic Computation and Economic Cybernetics Studies and Research; ASE Publishing; 54(2): 147-163;

[8] European Commission (2020), Digital Economy and Society Index (DESI). $E U$, https://ec.europa.eu/newsroom/dae/document.cfm?doc id=67086;

[9] European Commission (2021), Strategy, Shaping Europe's digital future, Policies, The Digital Economy and Society Index (DESI). EU, https://ec.europa.eu/digital-single-market/en/digital-economy-and-society-indexdesi;

[10] EUR-Lex (2015), Acces la dreptul UE, Strategia UE privind piaţa unică digital. Bruxelles, https://eur-lex.europa.eu/legal-content/RO/TXT/?uri=celex\%3A 52015DC0192;

[11] Eurostat (2021), Your key to European statistics. Eurostat, https://ec.europa.eu/eurostat;

[12] Fana, M., Tolan, S., Torrejon Perez, S., Urzi Brancati, M.C. , Fernandez Macias, E. (2020), The COVID Confinement Measures and EU Labour Markets. Publications Office of the European Union, Luxembourg, ISBN 978-92-76-188124, 1-28;

[13] Ghilic-Micu, B., Stoica, M. (2016), A Redefinition of Telework through

Cloud Computing - Telework 2.0, Bulletin of Taras Shevchenko National

University of Kyiv. Economics, 46(188): 16-21;

[14] Handy, C. (1993), Understanding Organizations. Penguin Adult Publishing House, ISBN 0140156038, 445;

[15] Liu, S. (2020), Internet of Things (IoT) - Statistics \& Facts. Statista, https://www.statista.com/topics/2637/internet-of-things/;

[16] Milasi, S., González-Vázquez, I, Fernández-Macías, E. (2021), Telework in the EU before and after the COVID-19: Where We were, Where We Head to.

European Commission, https://ec.europa.eu/jrc/sites/jrcsh/files/jrc120945 policy brief_covid_and_telework_final.pdf; 
Marian Stoica, Bogdan Ghilic-Micu, Marinela Mircea

[17] Ministry of Justice (2013), Methodological Norms Regarding the Transport Rights of Civil Servants with Special Status from the Penitentiary Administration System; Monitorul Oficial, Part I, 93;

[18] Mokhtarian, P. L. (1990), A Typology of Relationships between

Telecommunications and Transportation. Transportation Research Part A:

General, 24(3): 231-242;

[19] Nilles, J. (1998), Managing Telework: Strategies for Managing the Virtual Workforce. John Wiley \& Sons, Inc. ISBN: 978-0-471-29316-3, 5-352;

[20] Parlamentul României (2018), Legea nr. 81/2018 privind reglementarea activităţii de telemuncă. Monitorul Oficial, Partea I, 296, https://lege5.ro/gratuit/gi3tknrrgm2a/legea-nr-81-2018-privind-reglementareaactivitatii-de-telemunca;

[21] Sakovich, N. (2019), What Is the Internet of Everything (IoE)?. SaM

Solutions, https://www.sam-solutions.com/blog/what-is-internet-of-everything-ioe/; [22] Stoica, M., Ghilic-Micu, B. (2020), E-Government in Romania-A Case Study. Journal of e-Government Studies and Best Practices, 1-12, https://ibimapublishing.com/articles/JEGSBP/2020/608643/;

[23] Von Thünen, J. (2009), The Isolated State in Relation to Agriculture and Political Economy: Part III: Principles for the Determination of Rent, the Most Advantageous Value of Stands of Varying Age in Pinewoods. Palgrave Macmillan, ISBN 978-0230222519, 159. 